UCRL-CONF-203845

LA WRENCE LIWEAMCAE NATIONAL LABDAATOAY

Hyperdispersion Grating Arrangements for Compact Pulse Compressors and Expanders

D. N. Fittinghoff, W. A. Molander, and C. P. J. Barty

October 14, 2004

Frontiers In Optics Conference, Rochester, NY 10/10/04-10/14/04 


\section{Disclaimer}

This document was prepared as an account of work sponsored by an agency of the United States Government. Neither the United States Government nor the University of California nor any of their employees, makes any warranty, express or implied, or assumes any legal liability or responsibility for the accuracy, completeness, or usefulness of any information, apparatus, product, or process disclosed, or represents that its use would not infringe privately owned rights. Reference herein to any specific commercial product, process, or service by trade name, trademark, manufacturer, or otherwise, does not necessarily constitute or imply its endorsement, recommendation, or favoring by the United States Government or the University of California. The views and opinions of authors expressed herein do not necessarily state or reflect those of the United States Government or the University of California, and shall not be used for advertising or product endorsement purposes.

\section{Auspices Statement}

This work was performed under the auspices of the U.S. Department of Energy by University of California, Lawrence Livermore National Laboratory under Contract W-7405-Eng-48. 


\title{
Hyperdispersion grating arrangements for compact pulse compressors and expanders
}

\author{
David N. Fittinghoff, William A. Molander, and Christopher P. J. Barty \\ Lawrence Livermore National Laboratory, L-472 Livermore CA, 94551-0808 \\ fittinghoff1@,llnl.gov
}

\begin{abstract}
A novel, but general, arrangement of parallel sets of gratings is presented that can effectively increase the dispersion of pulse compressors and expanders by over an order of magnitude. These arrangements will dramatically reduce the footprint of the pulse compressors and expanders used in CPA.
\end{abstract}

\section{Introduction}

Chirped pulse amplification (CPA) [1] is a well-established technique for generation of high-intensity picosecond and femtosecond pulses. In CPA, grating arrangements are used to stretch pulses prior to amplification and compress them afterwards. The footprint of CPA pulse compressors and stretchers is proportional the dispersion of the gratings and to the inverse of the bandwidth of the pulse. For picosecond CPA, compressor-grating separations of several meters are not uncommon. Application of CPA to materials susch as Nd;YAG and Nd:YLF, whose bandwidth would limit compressed pulse durations to of order 5 ps or greater, would require impractically large parallel grating separations. In this paper, we will present a novel, but general, arrangement of parallel sets of gratings that effectively increase the dispersion of the pulse compressor by over an order of magnitude. These arrangements will dramatically reduce the footprint of the pulse compressors and expanders used in CPA systems. This will enable the practical application of CPA to common high-gain but narrow-bandwidth media such as $\mathrm{Nd}$ :YAG and Nd:YLF, and greatly simplify the generation of transform-limited, $\sim 1-10$ ps, high-energy pulses for precision micromachining, $\mathrm{X}$-ray generation, and lidar, etc.

\section{Compressor Example}

Shown in Fig. 1 is a generic arrangement of the hyperdispersion compressor. In this device, nested pairs of parallel gratings are used. The second grating of the configuration amplifies the angular dispersion of the first grating. The third and fourth gratings recollimated the

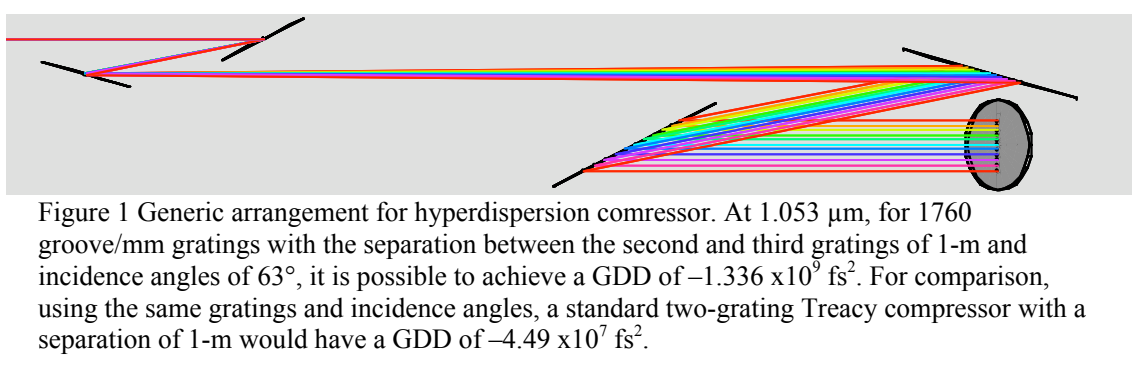
spectral content and produce a collimated but spatially dispersed pulse spectrum similar to that in a typical Treacy parallel-grating compressor [2]. By double passing the arrangement, the spatial chirp can be removed and the overall separation of the gratings required to produce a particular dispersion is reduced by a factor of 2 . Because of the amplified angular dispersion produced by the first two grating elements, the overall footprint (effective grating separation) of this device can be more than an order of magnitude less than a conventional two-grating Treacy compressor with the same dispersion. The principle drawback of this configuration is throughput, since the pulse experiences diffraction from 8 grating surfaces. However, recent advances in multi-layer dielectric (MLD) grating designs can produce diffraction efficiencies in excess of $99 \%$ [3], see Fig.2.

\section{References}

[1] D. Strickland and G. Mourou, "Compression of amplified chirped optical pulses," Opt. Commun., vol. 56, pp. 219-221, 1985. [2] E. B. Treacy, "Optical Pulse Compression With Diffraction Gratings," IEEE J. Quan. Electron., vol. QE-5, pp. 454-8, 1969.

[3] B. W. Shore, M. D. Perry, J. A. Britten, R. D. Boyd, M. D. Feit, H. T. Nguyen, R. Chow, G. E. Loomis, and L. Lifeng, "Design of high-efficiency dielectric reflection gratings," Journal of the Optical Society of America A-Optics \& Image Science, vol. 14, pp. 1124-36, 1997.

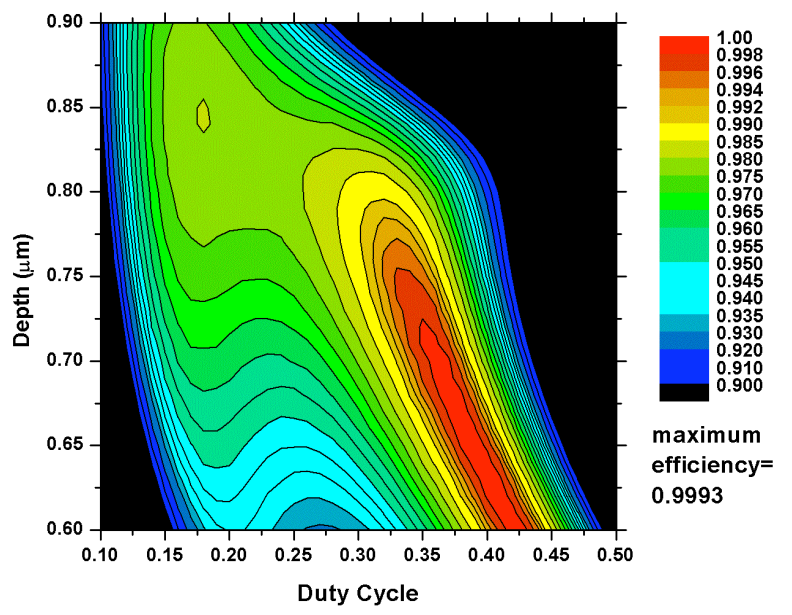

Figure 2 Diffraction efficiency versus groove depth and duty cycle for modern MLD grating design. 